\title{
A modified protocol for successful miRNA profiling in human precision-cut lung slices (PCLS)
}

\author{
Monika Niehof* ${ }^{*}$, Stella Marie Reamon-Buettner, Olga Danov, Tanja Hansen and Katherina Sewald
}

\begin{abstract}
Objective: Human precision cut lung slices (PCLS) are widely used as an ex vivo model system for drug discovery and development of new therapies. PCLS reflect the functional heterogeneity of lung tissue and possess relevant lung cell types. We thus determined the use of PCLS in studying non-coding RNAs notably miRNAs, which are important gene regulatory molecules. Since miRNAs play key role as mediators of respiratory diseases, they can serve as valuable prognostic or diagnostic biomarkers, and in therapeutic interventions, of lung diseases. A technical limitation though is the vast amount of agarose in PCLS which impedes (mi)RNA extraction by standard procedures. Here we modified our recently published protocol for RNA isolation from PCLS to enable miRNA readouts.

Results: The modified method relies on the separation of lysis and precipitation steps, and a clean-up procedure with specific magnetic beads. We obtained successfully quality miRNA amenable for downstream applications such as RTgPCR and whole transcriptome miRNA analysis. Comparison of miRNA profiles in PCLS with published data from human lung, identified all important miRNAs regulated in IPF, COPD, asthma or lung cancer. Therefore, this shows suitability of the method for analyzing miRNA targets and biomarkers in the valuable human PCLS model.
\end{abstract}

Keywords: miRNA extraction, RTqPCR, Microarray, miRNA array, RNA quality, Lung tissue, Lung material, Ex vivo, PCLS, Organotypic tissue

\section{Introduction}

MicroRNAs (miRNAs) are key transcriptional regulators of mRNA in eukaryotic cells. They are among the most abundant classes of gene regulatory molecules and control a wide range of biological functions including cellular proliferation, differentiation and apoptosis [1-3]. miRNAs are non-coding, single-stranded RNAs of 20-23 nucleotides and negatively regulate their mRNA targets by degrading and/or inhibiting protein translation. miRNAs may have a broad function in fine-tuning

\footnotetext{
*Correspondence: monika.niehof@item.fraunhofer.de
}

Department of Preclinical Pharmacology and In Vitro Toxicology,

Fraunhofer Institute for Toxicology and Experimental Medicine,

Biomedical Research in Endstage and Obstructive Lung Disease

Hannover (BREATH), Member of the German Center for Lung Research

(DZL), Nikolai-Fuchs-Str. 1, Hannover 30625, Germany the protein-coding genes and their discovery has revolutionized our understanding of gene regulation [4-6]. Many studies now link dysregulated miRNA expression to diseases, leading to their increasing importance as biomarkers and therapeutic agents [7-9]. The leading areas of miRNA diagnostics include the cancer field, neurological and cardiovascular diseases [3, 10, 11]. For therapeutic invention, approaches are made using miRNA mimics to inhibit tumor growth [12-15]. Furthermore, chemically-modified antisense oligonucleotides are used to interfere with miRNA function (antagomirs) $[16,17]$ and their therapeutic efficacy was already shown for example in a cardiovascular disease setting [18-20]. Some RNA therapeutics have been approved or in phase III trials [21]. Accumulating number of investigations show a pivotal role of miRNAs in the pathogenesis of respiratory

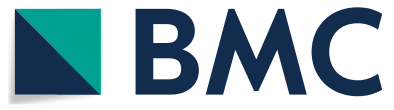

(c) The Author(s) 2021. This article is licensed under a Creative Commons Attribution 4.0 International License, which permits use, sharing, adaptation, distribution and reproduction in any medium or format, as long as you give appropriate credit to the original author(s) and the source, provide a link to the Creative Commons licence, and indicate if changes were made. The images or other third party material in this article are included in the article's Creative Commons licence, unless indicated otherwise in a credit line to the material. If material is not included in the article's Creative Commons licence and your intended use is not permitted by statutory regulation or exceeds the permitted use, you will need to obtain permission directly from the copyright holder. To view a copy of this licence, visit http://creativeco mmons.org/licenses/by/4.0/. The Creative Commons Public Domain Dedication waiver (http://creativecommons.org/publicdomain/ zero/1.0/) applies to the data made available in this article, unless otherwise stated in a credit line to the data. 
diseases such as fibrosis, asthma or chronic obstructive pulmonary disease (COPD) [22-27]. Given these central role of miRNAs in lung diseases, they are candidates for prognostic or therapeutic biomarkers and novel therapeutic approaches.

Precision-cut lung slices (PCLS) are widely used for discovery and development of new drugs and therapies in lung diseases [28]. They are thin viable sections of lung tissue which can be cultured under normal cell culture conditions and exposed to agents such as drugs, chemicals, nanoparticles, virus, bacteria or fungi [29]. PCLS reflect the functional heterogeneity of lung tissue and possess relevant cell types including airway and alveolar epithelial cells, smooth muscle cells, endothelial cells, and much more. Active populations of both innate and adaptive immune cells such as alveolar macrophages and T-cells can also be found in varying numbers within precision-cut lung slices. They have been proven to provide highly translational data [30, 31]. During work with PCLS the large amount of agarose in PCLS impedes RNA extraction according to standard procedures. Therefore, we recently published an optimized protocol for RNA isolation from PCLS to perform gene expression analysis in this valuable model [32]. Despite increasing importance of miRNAs, we did not find so far studies describing the isolation and analysis of miRNA derived from PCLS. We thus aimed to establish an optimized protocol for isolating total RNA including miRNA from PCLS. Here we show miRNA from PCLS amenable for downstream applications such as RTqPCR or whole transcriptome miRNA analysis. We also demonstrate the suitability of human PCLS as a model for lung specific miRNA investigations by comparing miRNA profiles of PCLS samples with published data from human lungs.

\section{Main text \\ Methods \\ Human lung tissue and PCLS preparation}

Human lung lobes were obtained from male and female patients who underwent lung resection for cancer. Tumor- free tissue was processed immediately on the day of resection. The average age of patients was $70 \pm 11$ years. PCLS preparation, cultivation and storage are described in detail in Additional file 1.

\section{Isolation of total RNA including miRNA}

RNA including miRNA was isolated using the Mag MAX mirVana Total RNA Isolation Kit (ThermoFisher Scientific) with several modifications. The detailed protocol and the RNA quality assessment are described in Additional file 1 .

\section{Quantitative real time RT-PCR analysis (RTqPCR)}

RTqPCR for miR-15a was performed using the miScript PCR system (Qiagen) and qPCR reactions were performed using an ABI PRISM 7500 real-time PCR detection system (Applied Biosystems). Detailed conditions and efficiency calculation are described in Additional file 1.

\section{Whole transcriptome miRNA analysis and data analysis}

Whole transcriptome miRNA analysis was performed using Affymetrix GeneChip ${ }^{\circledR}$ miRNA 4.0 arrays (ThermoFisher Scientific) according to the manufacturer's instructions. Briefly, $100 \mathrm{ng}$ of total RNA was labeled with biotin using the flashtag ${ }^{\mathrm{TM}}$ HSR RNA labeling kit (ThermoFisher Scientific) and then hybridized for $18 \mathrm{~h}$ at $48{ }^{\circ} \mathrm{C}$ with the array, which was subsequently washed, stained, and read out with a GeneChip ${ }^{\circledR}$ Scanner 3000 7G. The raw data are available at the Gene Expression Omnibus (GEO) site (http://www.ncbi.nlm.nih.gov/geo, accession number for this dataset GSE167705). Quality control of microarray analysis and visualization of the miRNA data were undertaken using metrics and methods contained in Transcriptome Analysis Console Software (TAC 4.0, Thermo Fisher Scientific) as described in detail in Additional file 1.

\section{Data comparison with published data from human lung}

We searched NCBI PubMed and the Gene Expression Omnibus (GEO) repository for miRNA profiles from human lungs, and, for instance, we downloaded Raw. CEL files from GSE81293 (Expression of miRNA from lung tissue from Systemic Sclerosis patients with interstitial lung disease (SSc-ILD) and healthy controls [33]. Detailed re-analysis and comparison of data was performed as described in Additional file 1. Furthermore, we compared our miRNA profiles with miRNAs that are implicated in respiratory diseases obtained from literature search.

\section{Results and discussion \\ Application of an optimized protocol for RNA isolation including miRNA from PCLS and assessment of miRNA by $R T q P C R$}

Inspired by our recently published protocol for RNA isolation [32], we established a protocol for isolation of total RNA including miRNA from PCLS which should be suited also for mRNA and miRNA analysis. We used in total 48 PCLS samples from three human donors and carried out treatments with five different substances at three different dose levels as indicated in Additional file 2: Table S1. All samples yielded good RNA quality, i.e. high RNA purity with an $\mathrm{A}_{260} / \mathrm{A}_{280}$ ratio around 
2.0 and high RNA integrity with a RIN value around 9.0 (Additional file 2: Table S1). Representative bioanalyzer results for RNA integrity with clear bands at $18 \mathrm{~s}$ and $28 \mathrm{~s}$ rRNA for $\mathrm{n}=10$ human PCLS are shown in Fig. 1a. Furthermore, we used Agilent Small RNA assays to visualize the presence of small RNAs in the total RNA preparation (Fig. 1b). As expected for inclusion of small RNAs in samples the miRNA region around 20 nucleotides was visible as a small hill, while great amounts of tRNAs (73-95 nt), small $5 \mathrm{~s}$ rRNAs (120 nt) and $5.8 \mathrm{~s}$ rRNA (160 nt) could be detected by peaks. Overall, the electropherogram clearly visualized the presence of small RNAs in the samples.

Next we analyzed the expression of miR-15a, which is highly expressed in human tissues, rendering it as an ideal positive control for validating miRNA isolation and RTqPCR quality assessment [6]. RTqPCR analysis of several human PCLS cDNA dilutions resulted in an accurate and linear detection $\left(r^{2}=0.9945\right)$ of miR-15a with high amplification efficiency $(E=91.2 \%)$ and a single peak in the melting curve (Fig. 1c). This shows also the suitability of the isolated miRNA derived from human PCLS for RTqPCR based miRNA expression analysis.

\section{Genome-wide miRNA profiling in human PCLS and detection of characteristic pulmonary miRNAs}

We performed genome-wide miRNA profiling for untreated control PCLS samples from $\mathrm{n}=10$ different donors. For comparison purposes with the control samples, we also included for analysis $n=9$ PCLS samples, which were treated with three different dose of a chemical compound for risk assessment screening. We analyzed the miRNA data using quality control metrics and visualization methods for gene expression arrays contained in the Transcriptome Analysis Console (TAC 4.0) software. In all the miRNA arrays, the signal values obtained for the 5' and 3' hybridization controls, i.e. cRNA of biotin genes bioB, bioC, and bioD from $E$. coli and cre gene from $\mathrm{P} 1$ bacteriophage, increased as expected from bioB to cre (Fig. 2a, b). This increase in the signal values for the hybridization controls was a reflection of their increasing relative concentrations. Thus, all the miRNA arrays passed the hybridization control metrics, which were used in monitoring hybridization efficiency. Moreover, all the miRNA arrays also passed the thresholds for spikein controls consisting of five oligonucleotide probe sets to confirm poly(A) tailing, ligation, and lack of RNAses in the RNA samples (Fig. 2c). A log 2 signal values $>9.96$ were obtained for the five oligonucleotide probe sets in all the miRNA arrays. We also inspected the signal box plot of CHP files after normalization using the RMA method and we found that the miRNA arrays did not differ dramatically from each other (Fig. 2d). Figure 2e shows the graph after Principal Component Analysis (PCA) on CHP files, while Fig. 2f shows the hierarchical clustering graph of filtered 75 miRNAs from the comparison of one
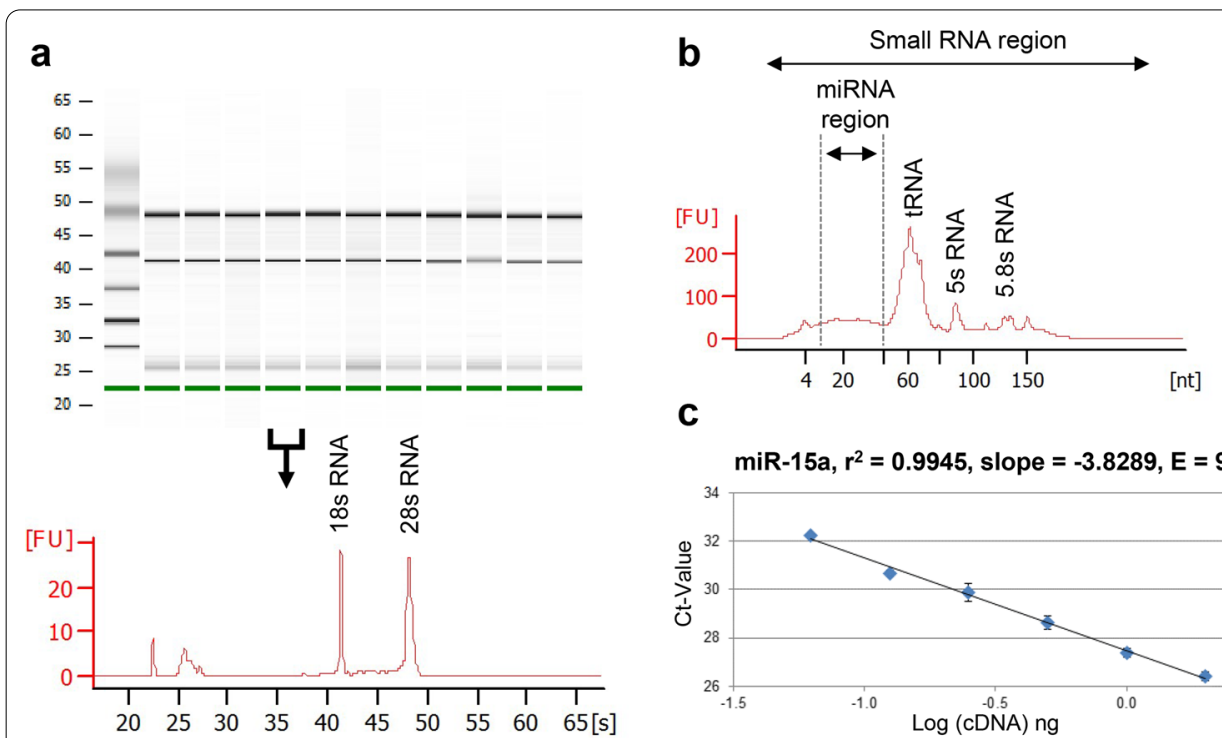

C
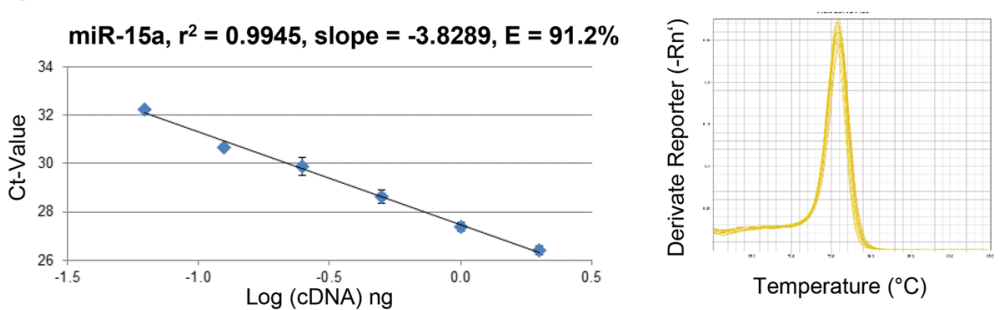

Fig. 1 Assessment of RNA quality for human PCLS. a Representative bioanalyzer results using Agilent RNA 600 Nano assay showing the integrity of RNA isolated from 10 different human PCLS samples (virtual RNA gel format and electropherogram depicting fluorescence units versus run time in seconds). $\mathbf{b}$ Representative bioanalyzer results using Agilent Small RNA assay visualizing the presence of small RNAs (electropherogram depicting fluorescence units versus run time in seconds). c miScript PCR assay for miR-15a, calibration curve and melting curve using several human PCLS cDNA dilutions 

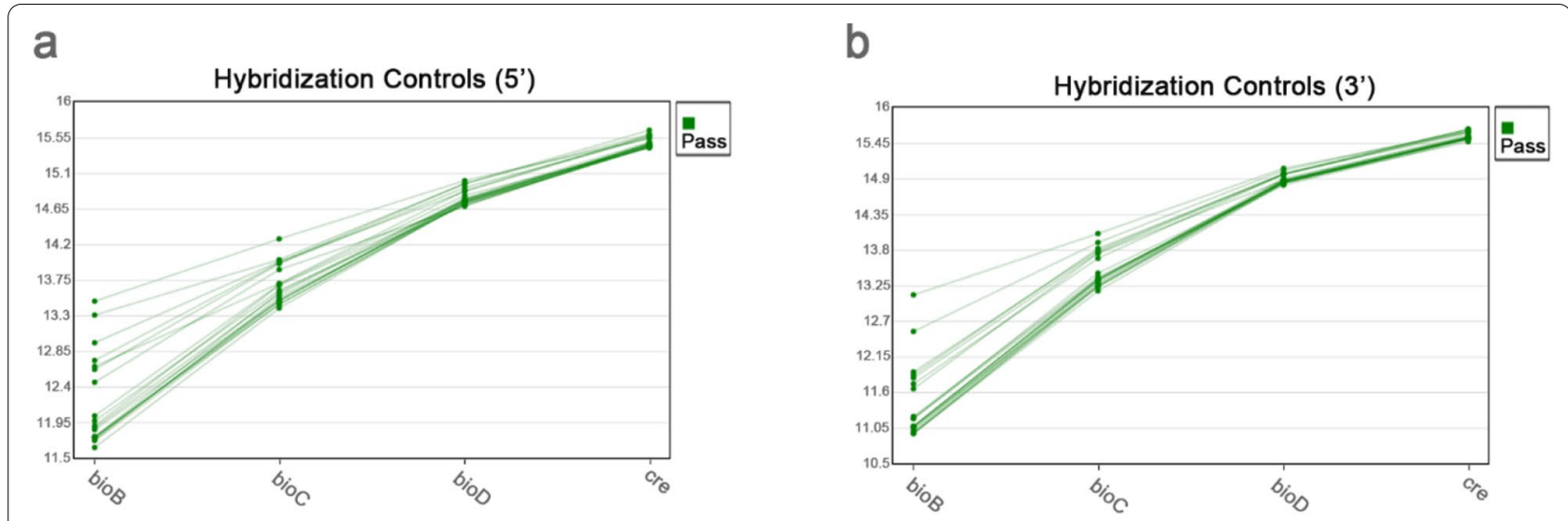

C

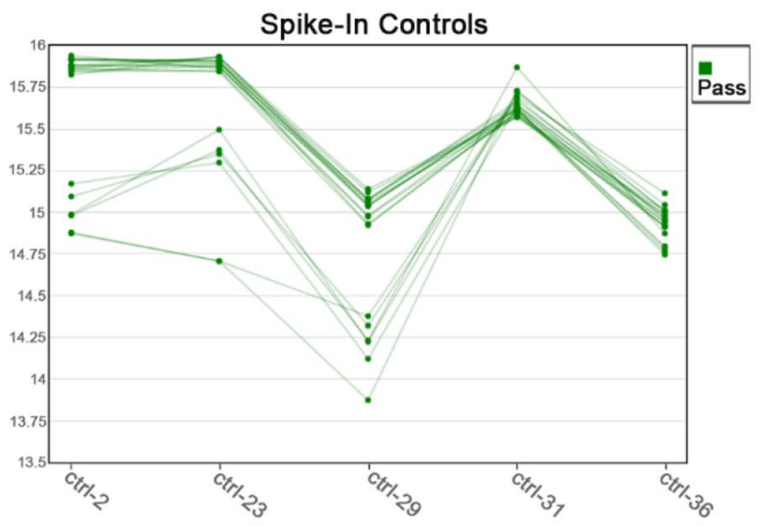

d
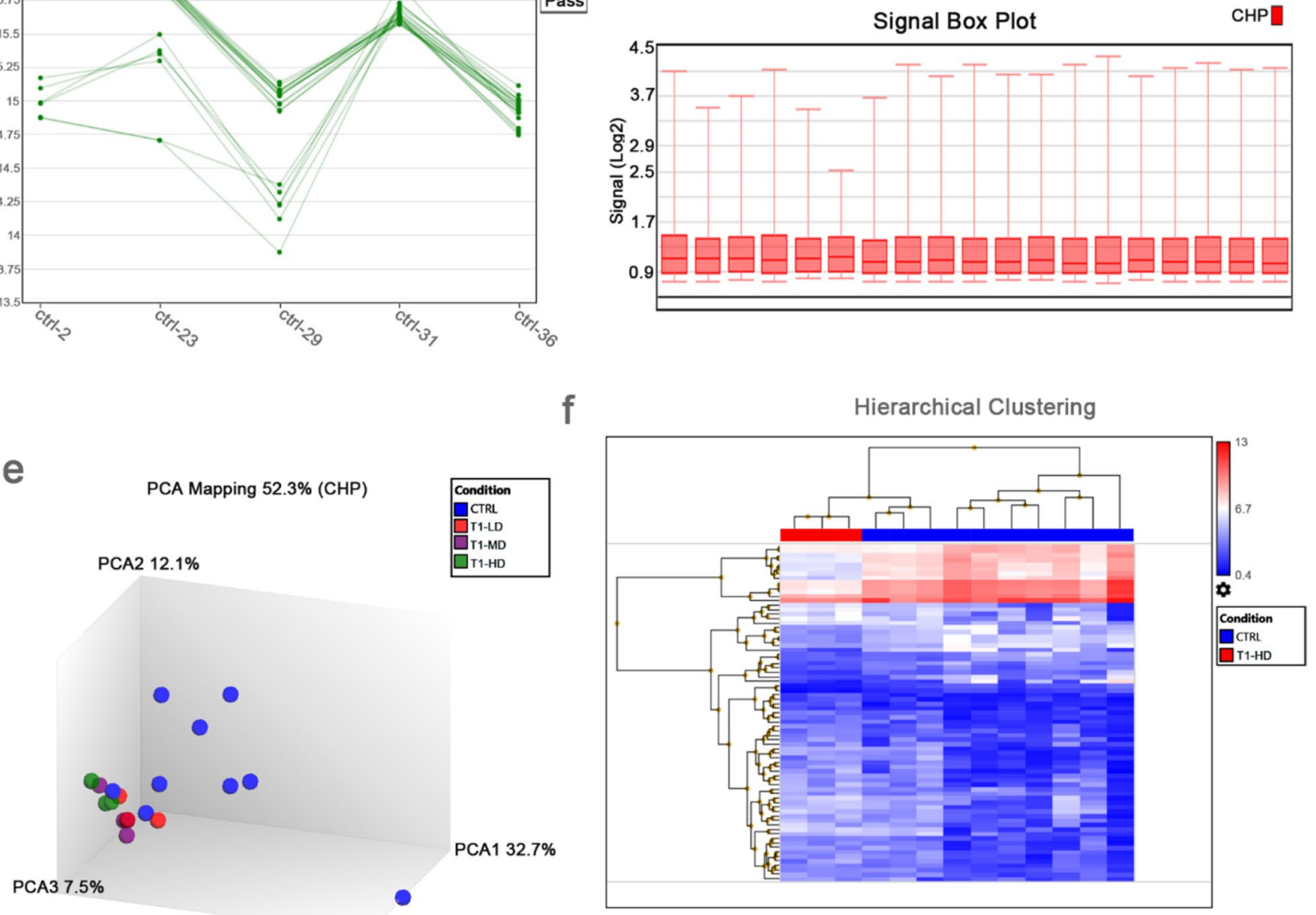

Fig. 2 Quality control of miRNA data. Affymetrix microarrays were subjected to quality control criteria specified in Transcriptome Analysis Console (TAC 4.0), i.e. (a, b) 5' and 3' hybridization controls, (c) spike-in controls and $\mathbf{d}$ signal box plot. e Principal component analysis (PCA) mapping of the miRNA data, showing majority of untreated control samples in one group and treated samples in another group. $\mathbf{f}$ Hierarchical clustering of filtered genes (Fold Change $<-2$ or $>2$, P-Value $<0.05,75$ miRNAs, listed in Additional file 5: Table S4) in samples treated with T1-HD vs. untreated control. $\mathrm{T} 1=$ Methyl acrylate (CAS 96-33-3), $\mathrm{LD}=0.1 \mathrm{mM}, \mathrm{MD}=0.3 \mathrm{mM}, \mathrm{HD}=1 \mathrm{mM}$ 
treatment group vs untreated control. In both PCA and hierarchical clustering graphs, we observed essentially separate clustering of treated samples especially in the high dose (HD) from the untreated ones. Heterogeneity was evident though in the control group presumably due to differences in donor origin.

The lung has a unique miRNA expression profile and characteristic miRNA signatures are linked to specific pathological condition $[5,24,34]$. Therefore, we assessed the miRNA profile obtained in human PCLS (Additional file 3: Table S2), according to the maintenance of characteristic pulmonary miRNAs. In detail, our data indicated that miR-195 and miR-200c which are uniquely expressed in lung were detected and that several important miRNAs for physiological lung functions [5, 34, 35] such as let-7, miR-145/146a/b, miR-155, miR-15/16/17, miR-26a and miR-29 were also expressed in human PCLS (Additional file 4: Table S3). We also checked the data for expression of characteristic miRNAs associated with specific pathological condition. Major miRNAs described in idiopathic pulmonary fibrosis with putative functions in aberrant inflammatory responses and in regulation of extra cellular matrix synthesis, collagen expression, matrix metalloproteases (MMP) expression and epithelial-mesenchymal transition [25, 27, 36, 37] such as let-7d, miR-145, miR-199, miR-200b/c, miR-21, miR-26a, miR-29a/c and miR-92a (and several others, see Additional file 4: Table S3) could be detected in human PCLS. miRNAs such as miR-125a/b, miR-145/146a, miR149, miR-15b and miR-199a (Additional file 4: Table S3) are described as mediators of the TGF $\beta$ signaling cascade and of genes with impact on the development and progression of COPD, inflammatory response, and airway epithelial repair after injury. They are involved in regulation of airway smooth muscle function, Th2 response activation, macrophage differentiation, recruitment of eosinophils, regulation of matrix metalloproteases, and intensification of unfolded protein responses which contributes to lung cell apoptosis and lung inflammation [25, 35, 38]. miRNAs described with important function in asthma are mainly involved in the promotion of chronic inflammation with effects on T helper 2 (Th2) cells [5, 25] such as miR-106a, miR-126, miR-145/146a, miR-181a,
miR-21 and miR-221/222, which were also detectable in PCLS (Additional file 4: Table S3). Furthermore, miRNAs have also been implicated in the regulation of cellular pathways including differentiation, proliferation and survival linked to cancer [5, 23, 35]. Some miRNAs which act as tumor suppressors are downregulated in lung cancer as e.g. members of the let-7 family, miR-100, miR-16 and miR200b, others as e.g. miR-146b, miR-155, miR-21 and miR-221/222 act in promoting tumor formation and were also detected (Additional file 4: Table S3). Overall, we show good comparison of our miRNA dataset (Additional file 3: Table S2) with published data from healthy human lung (GSE81293) [33] (Fig. 3). Indeed, of the lung disease-associated miRNAs compared, 59 of 65 miRNAs exhibited more or less similar expression in PCLS and in the lung tissue.

\section{Conclusion}

In summary, the presented protocol resulted in miRNA of high quality for transcriptome wide analysis and detection of important miRNAs for several pulmonary pathophysiological condition. Therefore, this method will be well suited to analyze miRNA targets and biomarkers in the human PCLS model.

\section{Limitations}

It would be desirable to compare our PCLS datasets with more datasets of healthy human lungs from the literature to confirm our results. However, as of today in the GEO data base only older Affymetrix array versions are additionally available and the TAC 4.0 software does not allow matching of these miRNA probe IDs with the current Affymetrix GeneChip ${ }^{\circledR}$ miRNA arrays version 4.0. Furthermore, the number of donors for PCLS datasets was limited. However, we feel confident that the presented protocol is suitable for downstream applications because it overcomes the limitations of miRNA isolation from PCLS based on agarose and that it resulted in the detection of the most characteristic pulmonary miRNAs. 


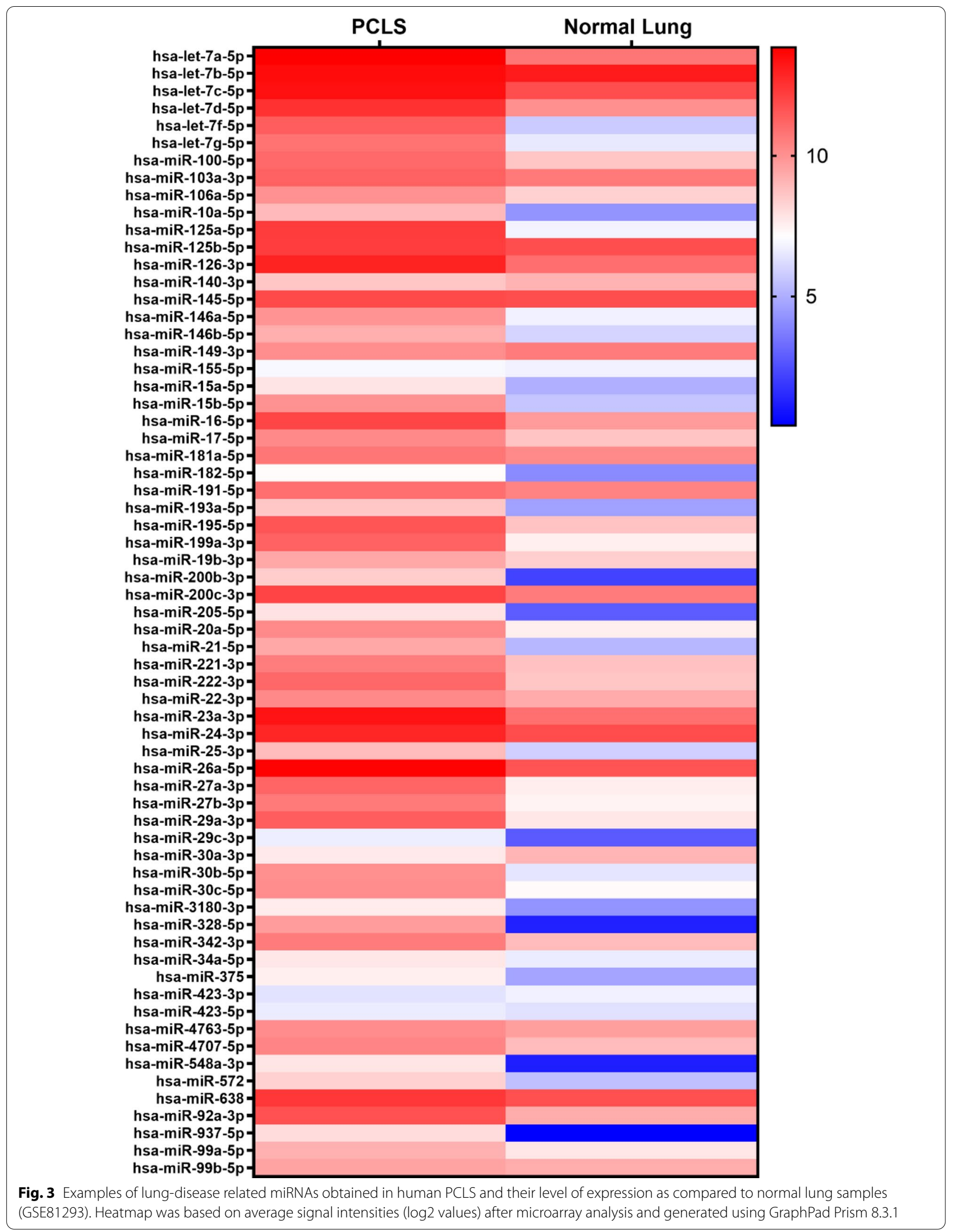




\begin{abstract}
Abbreviations
COPD: Chronic obstructive pulmonary disease; Cq: Quantification cycle; DMEM: Dulbecco's Modified Eagle Medium; EBSS: Earle's Balanced Salt Solution; HD: High dose; LD: Low dose; MD: Mid dose; MMP: Matrix metalloproteases; nt: Nucleotides; PCA: Principal component analysis; PCLS: Precision-cut lung slices; RIN: RNA integrity number; qPCR: Quantitative polymerase chain reaction; RT: Reverse transcriptase; T:Treatment; Th2 cells:T helper 2 cells.
\end{abstract}

\section{Supplementary Information}

The online version contains supplementary material available at https://doi. org/10.1186/s13104-021-05674-w.

\section{Additional file 1: Methods. \\ Additional file 2: Table S1. RNA yield from huPCLS after different treatments.}

Additional file 3: Table S2. List of filtered miRNAs obtained in human precision lung cut slices (PCLS).

Additional file 4: Table S3. A selected list of some miRNAs detected in human PCLS with already described function in pulmonary diseases.

Additional file 5: Table S4. List of filtered 75 differentially-expressed miRNAs in comparison T1-HD versus control used as basis during hierarchical clustering analysis.

\section{Acknowledgements}

The authors highly appreciate the valuable technical assistance of S.F. Schramm in PCLS cultivation and of A.K. Janze and A. Klauke in the miRNA work.

\section{Authors' contributions}

MN and SMRB conceived and designed the study, MN, SMRB and OD carried out the experimental work and collected the data, MN, SMRB, TH and KS performed data analysis, all authors wrote the manuscript, and all authors read and approved the final manuscript.

\section{Funding}

Open Access funding enabled and organized by Projekt DEAL. Parts of the study were funded by BMBF grant 031L0120A.

\section{Availability of data and materials}

The datasets generated and analyzed during the current study are available at GEO database GSE167705 and GSE81293 [33]

\section{Declarations}

\section{Ethics approval and consent to participate}

The experiments with human lung tissue were approved by the local ethics committee at the Hannover Medical School and are in accordance with The Code of Ethics of the World Medical Association (renewed on 04/22/2015, number 2701-2015). All patients gave written informed consent for using organ tissue for research.

\section{Consent for publication}

Not applicable.

\section{Competing interests}

The authors declare that they have no competing interests.

Received: 22 March 2021 Accepted: 24 June 2021

Published online: 02 July 2021

\section{References}

1. Esquela-Kerscher A, Slack FJ. Oncomirs - microRNAs with a role in cancer. Nat Rev Cancer. 2006;6:259-69. https://doi.org/10.1038/nrc1840.
2. Landgraf P, Rusu M, Sheridan R, Sewer A, lovino N, Aravin A, et al. A mammalian microRNA expression atlas based on small RNA library sequencing. Cell. 2007;129:1401-14. https://doi.org/10.1016/j.cell.2007.04.040.

3. Amiel J, de Pontual L, Henrion-Caude A. miRNA, development and disease. Adv Genet. 2012;80:1-36. https://doi.org/10.1016/B978-0-12404742-6.00001-6.

4. Ying S-Y, Chang DC, Lin S-L. The microRNA (miRNA): overview of the RNA genes that modulate gene function. Mol Biotechnol. 2008;38:257-68. https://doi.org/10.1007/s12033-007-9013-8.

5. Alipoor SD, Adcock IM, Garssen J, Mortaz E, Varahram M, Mirsaeidi M, Velayati A. The roles of miRNAs as potential biomarkers in lung diseases. Eur J Pharmacol. 2016;791:395-404. https://doi.org/10.1016/j.ejphar.2016. 09.015.

6. Liu T, Xu Z, Ou D, Liu J, Zhang J. The miR-15a/16 gene cluster in human cancer: A systematic review. J Cell Physiol. 2019;234:5496-506. https:// doi.org/10.1002/jcp.27342.

7. Conrad R, Barrier M, Ford LP. Role of miRNA and miRNA processing factors in development and disease. Birth Defects Res C Embryo Today. 2006;78:107-17. https://doi.org/10.1002/bdrc.20068.

8. Shah AA, Leidinger P, Blin N, Meese E. miRNA: small molecules as potential novel biomarkers in cancer. Curr Med Chem. 2010;17:4427-32. https://doi.org/10.2174/092986710794182980.

9. Thai T-H, Christiansen PA, Tsokos GC. Is there a link between dysregulated miRNA expression and disease? Discov Med. 2010;10:184-94.

10. Peng Y, Croce CM. The role of MicroRNAs in human cancer. Signal Transduct Target Ther. 2016;1:15004. https://doi.org/10.1038/sigtrans.2015.4.

11. Gupta SK, Bang C, Thum T. Circulating microRNAs as biomarkers and potential paracrine mediators of cardiovascular disease. Circ Cardiovasc Genet. 2010;3:484-8. https://doi.org/10.1161/CIRCGENETICS.110.958363.

12. Biswas S. MicroRNAs as therapeutic agents: the future of the battle against cancer. Curr Top Med Chem. 2018;18:2544-54. https://doi.org/10. 2174/1568026619666181120121830.

13. Iqbal MA, Arora S, Prakasam G, Calin GA, Syed MA. MicroRNA in lung cancer: role, mechanisms, pathways and therapeutic relevance. Mol Aspects Med. 2019;70:3-20. https://doi.org/10.1016/j.mam.2018.07.003.

14. Ors-Kumoglu G, Gulce-lz S, Biray-Avci C. Therapeutic microRNAs in human cancer. Cytotechnology. 2019;71:411-25. https://doi.org/10.1007/ s10616-018-0291-8.

15. Karmakar S, Kaushik G, Nimmakayala R, Rachagani S, Ponnusamy MP, Batra SK. MicroRNA regulation of K-Ras in pancreatic cancer and opportunities for therapeutic intervention. Semin Cancer Biol. 2019;54:63-71. https://doi.org/10.1016/j.semcancer.2017.11.020.

16. Krützfeldt J, Rajewsky N, Braich R, Rajeev KG, Tuschl T, Manoharan M, Stoffel M. Silencing of microRNAs in vivo with "antagomirs." Nature. 2005;438:685-9. https://doi.org/10.1038/nature04303.

17. Smith CIE, Zain R. Therapeutic oligonucleotides: state of the art. Annu Rev Pharmacol Toxicol. 2019;59:605-30. https://doi.org/10.1146/annurevpharmtox-010818-021050.

18. Thum T, Gross C, Fiedler J, Fischer T, Kissler S, Bussen M, et al. MicroRNA-21 contributes to myocardial disease by stimulating MAP kinase signalling in fibroblasts. Nature. 2008:456:980-4. https://doi.org/10.1038/nature07511.

19. Thum T. MicroRNA therapeutics in cardiovascular medicine. EMBO Mol Med. 2012:4:3-14. https://doi.org/10.1002/emmm.201100191.

20. Dangwal S, Thum T. microRNA therapeutics in cardiovascular disease models. Annu Rev Pharmacol Toxicol. 2014;54:185-203. https://doi.org/ 10.1146/annurev-pharmtox-011613-135957.

21. Wang F, Zuroske T, Watts JK. RNA therapeutics on the rise. Nat Rev Drug Discov. 2020;19:441-2. https://doi.org/10.1038/d41573-020-00078-0.

22. Dymacek J, Snyder-Talkington BN, Porter DW, Mercer RR, Wolfarth MG, Castranova $\mathrm{V}$, et al. mRNA and miRNA regulatory networks reflective of multi-walled carbon nanotube-induced lung inflammatory and fibrotic pathologies in mice. Toxicol Sci. 2015;144:51-64. https://doi.org/10.1093/ toxsci/kfu262.

23. Booton R, Lindsay MA. Emerging role of MicroRNAs and long noncoding RNAs in respiratory disease. Chest. 2014;146:193-204. https://doi.org/10. 1378/chest.13-2736.

24. Maltby S, Plank M, Tay HL, Collison A, Foster PS. Targeting MicroRNA function in respiratory diseases: mini-review. Front Physiol. 2016;7:21. https:// doi.org/10.3389/fphys.2016.00021.

25. Dutta RK, Chinnapaiyan S, Unwalla H. Aberrant MicroRNAomics in pulmonary complications: implications in lung health and diseases. Mol Ther 
Nucleic Acids. 2019;18:413-31. https://doi.org/10.1016/j.omtn.2019.09. 007.

26. Cho SJ, Lee M, Stout-Delgado HW, Moon J-S. DROSHA-Dependent miRNA and AIM2 Inflammasome Activation in Idiopathic Pulmonary Fibrosis. Int J Mol Sci. 2020. https://doi.org/10.3390/ijms21051668.

27. Wang Y, Xiao H, Zhao F, Li H, Gao R, Yan B, et al. Decrypting the crosstalk of noncoding RNAs in the progression of IPF. Mol Biol Rep. 2020;47:3169-79. https://doi.org/10.1007/s11033-020-05368-9.

28. Liu G, Betts C, Cunoosamy DM, Åberg PM, Hornberg JJ, Sivars KB, Cohen TS. Use of precision cut lung slices as a translational model for the study of lung biology. Respir Res. 2019;20:162. https://doi.org/10.1186/ s12931-019-1131-X.

29. Sewald K, Braun A. Assessment of immunotoxicity using precision-cut tissue slices. Xenobiotica. 2013;43:84-97. https://doi.org/10.3109/00498 254.2012.731543.

30. Delgado SJ, Dehmel S, Twisterling E, Wichmann J, Jonigk D, Warnecke $G$, et al. Disruptive anti-lgE inhibitors prevent mast cell-dependent early airway response in viable atopic lung tissue. J Allergy Clin Immunol. 2020;145:719-722.e1. https://doi.org/10.1016/j.jaci.2019.11.002.

31. Danov $\mathrm{O}$, Jiménez Delgado $S M$, Obernolte $H$, Seehase $S$, Dehmel $S$, Braubach $\mathrm{P}$, et al. Human lung tissue provides highly relevant data about efficacy of new anti-asthmatic drugs. PLoS ONE. 2018;13: e0207767. https://doi.org/10.1371/journal.pone.0207767.

32. Niehof M, Hildebrandt T, Danov O, Arndt K, Koschmann J, Dahlmann F, et al. RNA isolation from precision-cut lung slices (PCLS) from different species. BMC Res Notes. 2017;10:121. https://doi.org/10.1186/ s13104-017-2447-6.
33. Christmann RB, Wooten A, Sampaio-Barros P, Borges CL, Carvalho CRR, Kairalla RA, et al. miR-155 in the progression of lung fibrosis in systemic sclerosis. Arthritis Res Ther. 2016;18:155. https://doi.org/10.1186/ s13075-016-1054-6.

34. Sessa R, Hata A. Role of microRNAs in lung development and pulmonary diseases. Pulm Circ. 2013;3:315-28. https://doi.org/10.4103/2045-8932. 114758.

35. Sittka A, Schmeck B. MicroRNAs in the lung. Adv Exp Med Biol. 2013:774:121-34. https://doi.org/10.1007/978-94-007-5590-1 7.

36. Pandit KV, Milosevic J. MicroRNA regulatory networks in idiopathic pulmonary fibrosis. Biochem Cell Biol. 2015;93:129-37. https://doi.org/10. 1139/bcb-2014-0101.

37. Bagnato G, Roberts WN, Roman J, Gangemi S. A systematic review of overlapping microRNA patterns in systemic sclerosis and idiopathic pulmonary fibrosis. Eur Respir Rev. 2017. https://doi.org/10.1183/16000 617.0125-2016.

38. Szymczak I, Wieczfinska J, Pawliczak R. Molecular Background of miRNA Role in Asthma and COPD: An Updated Insight. Biomed Res Int. 2016;2016:7802521. https://doi.org/10.1155/2016/7802521.

\section{Publisher's Note}

Springer Nature remains neutral with regard to jurisdictional claims in published maps and institutional affiliations.
Ready to submit your research? Choose BMC and benefit from:

- fast, convenient online submission

- thorough peer review by experienced researchers in your field

- rapid publication on acceptance

- support for research data, including large and complex data types

- gold Open Access which fosters wider collaboration and increased citations

- maximum visibility for your research: over 100M website views per year

At BMC, research is always in progress.

Learn more biomedcentral.com/submissions 